\title{
Sound reduction in heat exchanger modules by integrating plate absorbers with sub-millimeter openings
}

\author{
Felix Czwielong ${ }^{1, *}$ (D), Sebastian Floss ${ }^{2}$ (D), Manfred Kaltenbacher ${ }^{2,3}$ (D), and Stefan Becker ${ }^{1}$ \\ ${ }^{1}$ Institute of Process Machinery and Systems Engineering, Friedrich-Alexander-University Erlangen-Nuernberg, 91058 Erlangen, \\ Germany \\ ${ }^{2}$ Institute of Mechanics and Mechatronics E325-3, TU Wien, 1040 Vienna, Austria \\ ${ }^{3}$ Institute of Fundamentals and Theory in Electrical Engineering, TU Graz, 8010 Graz, Austria
}

Received 31 March 2021, Accepted 27 May 2021

\begin{abstract}
In air conditioning systems heat exchangers are frequently installed upstream of ventilators. These modules are part of the daily life of humans and should therefore create an environment that is as quiet as possible. The heat exchanger generates increased turbulence, which leads to increased sound emissions of the ventilator. Due to installation space limitations, it is not possible to connect silencers to the heat exchanger module. A novel concept is presented, which allows to reduce the sound emissions of heat exchanger due to plate absorbers without the need of additional installation room. The plates contain sub-millimeter openings. They are integrated into the heat exchanger housing together with back volumes. This arrangement guarantees compactness and generates no additional flow resistance. The emitted sound could be reduced by up to $2.9 \mathrm{~dB}$ in the partial load range. The main advantages of the concept presented are individual adjustment, cost-effective design and simple installation.
\end{abstract}

Keywords: Heat exchanger, Axial fan, MPA, MPP, Sound reduction

\section{Introduction}

Axial fans are used in many installations for cooling and conveying gases. These machines have to fulfill high requirements with regard to sound emissions, which is due to their close proximity to people. If axial fans are used together with heat exchangers as heat exchanger modules, such as in air conditioning systems or cooling circuits, a higher sound level is often emitted [1,2]. This is due to the effect that the heat exchanger interferes with the flow field of the axial fan, thus amplifying the sound generation mechanisms at the axial fan. To counteract these increased sound emissions, either the flow guidance of the heat exchanger could be optimized, the axial fan could be designed for specific inflow turbulence, sound-reducing modifications to the fan such as serrations, slits or porous materials could be used, or classic silencers could be connected upstream or downstream of the heat exchanger module [3-6]. However, these noise reduction measures have so far only been used to a limited extent in industrial applications. This is due to the fact that optimization of the heat exchanger is a costly and time-consuming undertaking, axial fans are used in a variety of systems and thus cannot be optimized for a specific case, blade modifications often reduce sound emissions but also lower the efficiency of the machine,

*Corresponding author: cz@ipat.fau.de and additional silencers cannot be used due to the additional installation space required as well as increased pressure loss [7, 8]. Promising results have already been achieved with micro-perforated sound absorbers (MPA). These offer the advantage that they do not generate any additional pressure loss and can be designed for corresponding frequency-specific absorption levels. These sound absorbers have already been integrated, for example, in the direct proximity of axial fans in ducts, in HVAC systems or in rooms [9-16]. In addition, MPAs offer the properties that they are non-flammable, do not concentrate toxic substances, and do not pose a risk to humans from accumulated viruses or smallest fibers. These advantages make MPA suitable for use in heat exchanger modules. In this study, a novel concept is presented on how MPA can be integratesd into heat exchanger modules to reduce sound emissions. The focus is on not generating any additional pressure loss and thus maintaining the efficiency of the system. In addition, the design should be as space-saving and simple to implement as possible.

\section{Theory and design of micro-perforated absorbers}

The MPA consists of a micro-perforated plate (MPP, [17]) with impedance $Z_{\mathrm{MPP}}$ and an air-tight back volume 


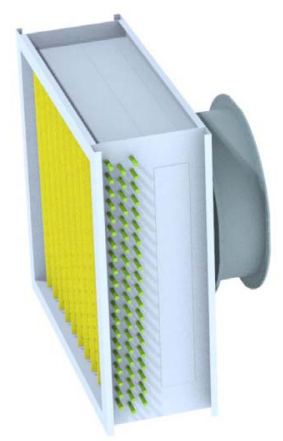

(a) Original heat exchanger modul

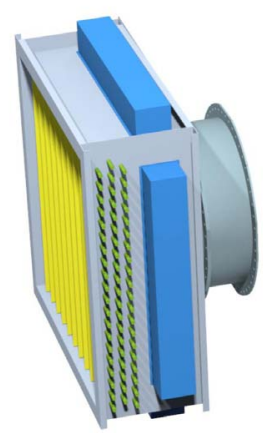

(b) Heat exchanger exterior view

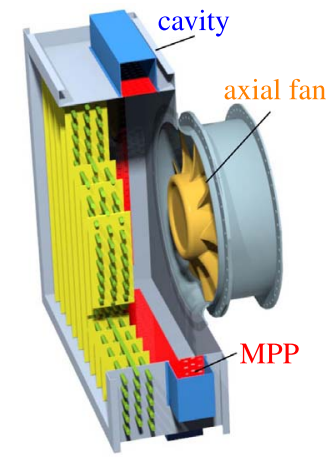

(c) Heat exchanger sectional view

Figure 1. Reference heat exchanger module (heat exchanger + axial fan) with rigid walls (a) and modified case with built-in MPP (red) and additional cavities (blue) (b and c). Heat exchanger consists of housing (gray), coolant tubes (green) and cooling fins (yellow).

of a certain length with impedance $Z_{\text {cav }}$. The damping range of the MPA can be estimated by the use of twopole-network theory [18]. Thereby, the MPP domain is simulated as an equivalent fluid $[19,20]$ with angular frequency $\omega$ dependent density $\tilde{\rho}(\omega)$. The absorption coefficient $\alpha$ is computed with the characteristic impedance of air $Z_{\text {air }}$ according to [21]:

$$
\begin{gathered}
\tilde{\rho}(\omega)=\frac{\alpha_{\infty} \rho_{0}}{\phi}\left[1+\frac{\sigma \phi}{j \omega \rho_{0} \alpha_{\infty}} \sqrt{1+j \frac{4 \alpha_{\infty}^{2} \eta_{0} \rho_{0} \omega}{\sigma^{2} \Lambda^{2} \phi^{2}}}\right], \\
\tilde{Z}_{m}(\omega)=\sqrt{\tilde{\rho}_{m}(\omega) K_{0}}=\frac{T_{m, 11}}{T_{m, 21}} ; \quad m=0,1, \\
\alpha=1-\left|\frac{Z_{\text {eff }}-Z_{\text {air }}}{Z_{\text {eff }}+Z_{\text {air }}}\right|^{2} \quad \text { with } \quad Z_{\text {eff }}=Z_{\mathrm{MPP}=1}+Z_{\text {cav }=0} .
\end{gathered}
$$

In (1) and (2) $K_{0}$ and $\rho_{0}$ denote the bulk modulus and density of air at ambient conditions, $\phi$ is the porosity of the MPP, $\sigma$ the specific flow resistance and $\Lambda$ the viscous characteristic length of the MPP. Furthermore, $\eta_{0}$ is the dynamic viscosity of air and $\alpha_{\infty}$ is a length correction factor [22]. The computed absorption coefficient in (3) can be explored to tune the MPA to a specific noise frequency range.

\section{Micro-perforated plates, heat exchanger and axial fan}

Classical heat exchanger modules consist of two main components the heat exchanger and an axial fan, which is needed to generate the volume flow through the heat exchanger. The heat exchanger consists of three components, the housing, the coolant tubes and the cooling fins. The axial fan is located at a defined distance downstream from the cooling fins. In order to economize space and to keep the axial size of the module as small as possible, the
Table 1. Key characteristics of the axial fans.

\begin{tabular}{lc}
\hline Parameter & Value \\
\hline Duct diameter & $500 \mathrm{~mm}$ \\
Fan diameter & $495 \mathrm{~mm}$ \\
Hub diameter & $247.5 \mathrm{~mm}$ \\
Tip gap size & $2.5 \mathrm{~mm}$ \\
Fan blade number & $9 \mathrm{blades}^{-1}$ \\
Design volume flow & $1.4 \mathrm{~m}^{3} \mathrm{~s}^{-1}$ \\
Operating speed & $1486 \mathrm{~min}^{-1}$ \\
NACA-profile & NACA $4510[28]$
\end{tabular}

axial fan is operated directly inside an inlet nozzle, which is connected to a short duct segment. For the experimental investigations of the heat exchanger modules, a real module is installed in an axial fan test bench. The arrangement of the module used (see Fig. 1) represents a practice-relevant configuration which is used in many small to medium-sized cooling units. The test bench is designed in accordance with DIN EN ISO 5801 [23] and has a low-reflection chamber on the suction side. For the investigations a forward skewed axial fan and a heat exchanger with a square surface $(800 \mathrm{~mm} \times 800 \mathrm{~mm})$ are used. The key characteristics of the axial fan and the heat exchanger used are given in Tables 1 and 2. For acoustic and aerodynamic studies of the axial fan used, the reader is referred to literature $[1,24,25]$. The sound emissions of the modules are measured by five free-field microphones $(\mathrm{B} \& \mathrm{~K})$, which are located at a distance of $R=1000 \mathrm{~mm}$ from the axial fan, within the low-reflection chamber $[6,9]$. On the basis of this measurement data, the overall sound pressure level from the spatially distributed microphones is calculated and, in addition, the insertion loss between the modified modules and the unmodified reference heat exchanger is evaluated $[26,27]$.

Heat exchangers are often installed in places and systems where no further room for silencers is available. Conventional silencers would lead to an enlargement of the system in the axial direction and in most cases mean an additional pressure loss, which lowers the efficiency of the 
Table 2. Key characteristics of the heat exchanger.

\begin{tabular}{lc}
\hline Parameter & Value \\
\hline Width & $800 \mathrm{~mm}$ \\
Height & $800 \mathrm{~mm}$ \\
Length & $330 \mathrm{~mm}$ \\
Coolant tube rows & 3 \\
Coolant tubes per row & 20 \\
Coolant tube diameter & $10 \mathrm{~mm}$ \\
Cooling fins spacing & $2 \mathrm{~mm}$ \\
Cooling fins length & $104 \mathrm{~mm}$ \\
Space between fan and fins & $216 \mathrm{~mm}$ \\
\hline
\end{tabular}

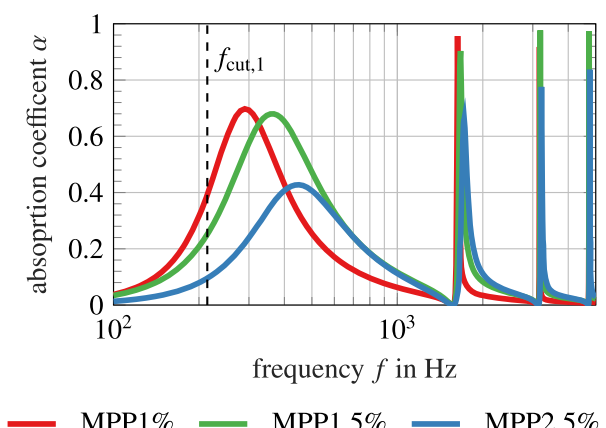

Figure 2. Estimated absorption coefficient from JCAL-model and cut-off frequency (dashed line).

system. MPAs, on the other hand, can be installed parallel to the flow and generate only a small pressure loss. In order to keep the additional axial dimensioning, a novel, spacesaving MPA application is investigated. This MPA is inserted into the unused installation space between the cooling fins and the axial fan, see Figure 1c. For this purpose, parts of the rigid housing wall of the unmodified heat exchanger (in this paper this heat exchanger is used as reference case, see Fig. 1a) are replaced by MPP and equipped with a cavity. This arrangement only requires a small additional space for the cavities, which are mounted perpendicular to the flow direction.

In these investigations, a MPA with a cavity length of $D=108 \mathrm{~mm}$ is used. Three different MPPs with different perforations $(\phi=1 \% ; 1.5 \% ; 2.5 \%)$ are examined. An MPA consisting of cavity and MPP is integrated on each outer side of the heat exchanger. The area dimensions of the MPP are $L=700 \mathrm{~mm}$ length and $W=100 \mathrm{~mm}$ wide. The thickness of the MPP is $t=1.5 \mathrm{~mm}$.

Using the JCAL model [29] and the measured characteristics, the absorption coefficient $\alpha$ of the MPAs can be estimated cost-effectively and in a fast way in advance, see Figure 2. In this design, a high absorption in the low frequency range around $300 \mathrm{~Hz}$ was aimed for. In this frequency range, increased sound emissions occur due to tip gap flow in the investigated axial fan. This leads to undesired high sound emissions, especially in the partial load range [24].

The calculation of the absorption coefficient assumes a plane wave propagation within the heat exchanger. Based

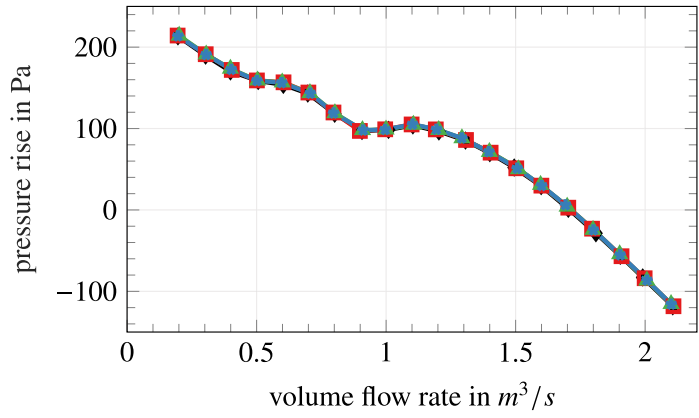

(a) total-to-static pressure rise (fan+hex)

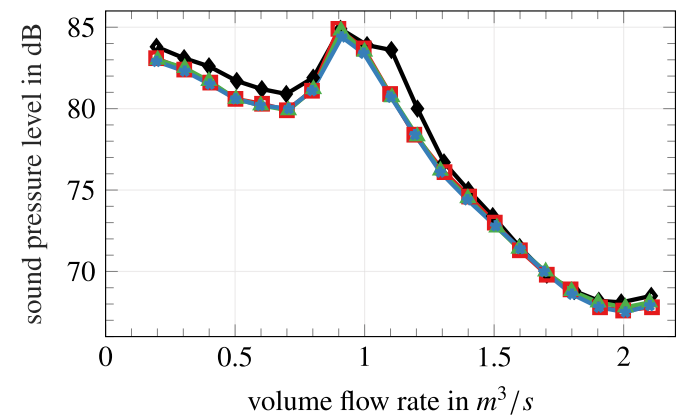

(b) overall sound pressure level (fan+hex)

$\neg$ Ref $\because$ MPP1\% - MPP1.5\% $-\mathrm{MPP} 2.5 \%$

Figure 3. Characteristic curves of the forward skewed axial fan with heat exchangers, (a) aerodynamic curve and (b) acoustic curve.

on Equation (4) the cut-off frequency inside the heat exchanger can be determined to $214 \mathrm{~Hz}$. This means that above this frequency higher modes can propagate and the calculated absorption coefficient can only be understood as a first estimation [30]:

$$
f_{\text {cut }, 1}=0.5 \cdot n \cdot \frac{c}{b}=0.5 \cdot 1 \cdot \frac{343 \mathrm{~ms}^{-1}}{0.8 \mathrm{~m}}=214 \mathrm{~Hz} .
$$

It should be noted that the model used also does not represent the influence of flow on the MPA. However, it can be used as a simplified tool to get a first impression of the sound absorption of the MPA without costly characterization measurements of the flow and sound field over the MPA.

\section{Acoustic and aerodynamic behavior of MPP in heat exchanger arrangements}

The innovative concept of integrating MPA silencers in the side walls of heat exchangers was investigated in terms of aerodynamic and acoustic properties. The investigations were carried out in a standardized axial fan test rig with an anechoic chamber. Figure 3 shows the aerodynamic characteristic curve of the heat exchanger module and the acoustic characteristic curve of the system. Regarding the pressure rise, it was found that the integration of MPA in the side walls of the heat exchangers does not cause any additional pressure loss. As a result, the efficiency of the complete heat 
exchanger module remains unchanged. Similar observations could already be found in other investigations and can be attributed to the good flow guidance of the MPPs [9, 12]. These have a high flow resistance due to the submillimeter openings, which means that only a small amount of the flow passes through the openings of the MPP. A constant efficiency is a major advantage of the novel concept, because no additional energy is required to overcome the flow resistance, as is the case, for example, with classic sound absorbers, which are arranged in the direction of flow.

The acoustic characteristic curve shows that the integrated MPA reduces the sound pressure level in the partial load range $\left(\dot{V}<1.4 \mathrm{~m}^{3} \mathrm{~s}^{-1}\right)$. The highest sound reduction of $2.9 \mathrm{~dB}$ occurs at a flow rate of $\dot{V}=1.1 \mathrm{~m}^{3} \mathrm{~s}^{-1}$ at which the second subharmonic peak dominates the sound pressure spectrum of the used fan. With a cavity length of $108 \mathrm{~mm}$, the MPA was designed precisely for this frequency range, which should reduce the sound pressure level when the axial fan is not operating at the design point but in the partial load range. At the design point, a sound reduction of $0.6 \mathrm{~dB}$ can be observed. At higher volume flows, this reduction decreases further and increases again slightly in the full load range. By changing the MPP area and the cavity length, the sound reductions can be increased (larger absorber area results in higher absorption) and other frequency ranges can be targeted (maximum absorption at $\lambda / 4$ of the cavity length). This variability and individual adjustment is another advantage of the MPA.

Based on the insertion loss, the frequency ranges in which a sound reduction occurs due to the MPA can be identified, see Figure 4. Negative values of the insertion loss indicate sound reductions. For all three shown operating points, a sound reduction at $f \in[260 \mathrm{~Hz} ; 440 \mathrm{~Hz}]$ can be determined. For this frequency range, the second subharmonic peak in the sound spectrum of the investigated axial fan occurs. Maximum reductions of up to $8.5 \mathrm{~dB}$ at a frequency of $372 \mathrm{~Hz}$ can be achieved. The different porosities of the MPP show only minor differences in the insertion loss. However, slightly higher sound reductions are evident with increasing porosity. This shows the opposite tendency to the previously estimated absorption coefficient. These differences may be related to higher modes, which are already present in this frequency range. Since the porosities have only a minor influence on the insertion loss, it can be concluded that the major part of the sound reduction is due to the cross-sectional expansion caused by the cavity and that the MPP mainly serve as a flow guidance in this case. At the operating point $\dot{V}=1.4 \mathrm{~m}^{3} \mathrm{~s}^{-1}$, only small reductions in the total sound pressure level could be achieved, see Figure 3b. From the insertion loss it can be seen that the blade passing frequencies $\left(f_{\mathrm{BPF}}=223 \mathrm{~Hz}\right)$ and the first harmonic $\left(f_{1}=446 \mathrm{~Hz}\right)$ were increased due to the MPA. In contrast, the second harmonic $\left(f_{2}=669 \mathrm{~Hz}\right)$ was reduced. This indicates that although the MPA does not contribute to the pressure loss of the system (Fig. 3a), the rough surface of the MPP may change the turbulence characteristics such as turbulence intensity and length scales, which in turn leads to changed sound radiation at the blade passing frequency and its harmonics. This effect is undesirable but also

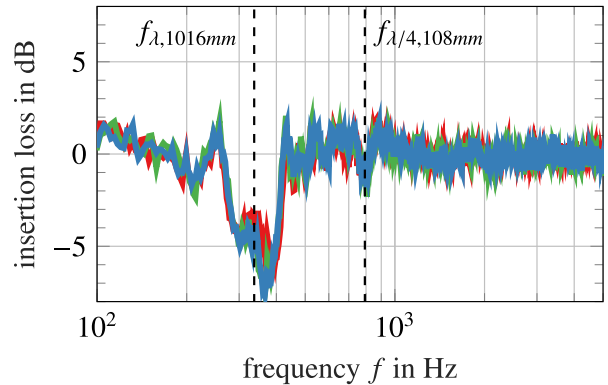

(a) $\dot{V}=0.8 \mathrm{~m}^{3} \mathrm{~s}^{-1}$

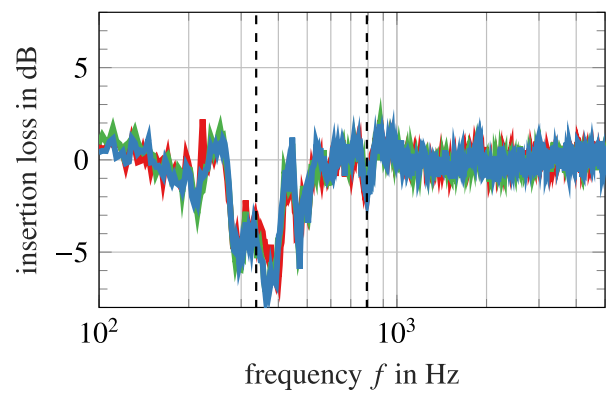

(b) $\dot{V}=1.1 \mathrm{~m}^{3} \mathrm{~s}^{-1}$

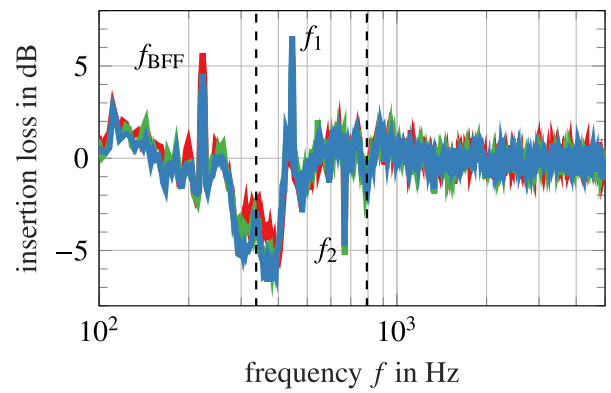

(c) $\dot{V}=1.4 \mathrm{~m}^{3} \mathrm{~s}^{-1}$

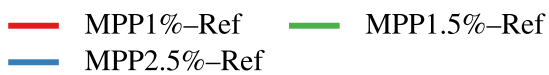

Figure 4. Insertion loss between the modified heat exchangers with MPA and the unmodified reference heat exchanger (rigid walls and without cavity) at different operating points.

provides further optimization possibilities for the integrated MPA. For example, MPPs with lower surface irregularities could reduce this undesirable side effect. The absorption at $f_{\lambda / 4,108 \mathrm{~mm}}=793 \mathrm{~Hz}$ is due to the $\lambda / 4$ resonator between the cavity and the MPP. In addition, it can be seen that the standing wave $\left(f_{\lambda, 1016 \mathrm{~mm}}\right)$, which forms between the cavity on one side and the cavity on the other side (distance $1016 \mathrm{~mm}$ ), counteracts the absorption of the MPA with increasing volume flow.

\section{Conclusion}

In this short communication a new concept to integrate MPAs into heat exchanger modules has been presented. The concept is based on the idea of converting existing and unused installation space of heat exchanger modules into active MPAs surfaces. The side walls of the heat exchanger, which serve to guide the flow, were replaced 
with an MPP and expanded by a cavity. This compact design has the advantage that no additional axial length in the direction of flow is necessary. In addition, this concept proved to be beneficial in terms of aerodynamic pressure loss. Due to the perforations in submillimeter range, flow guidance is provided by the MPP and no additional pressure loss is generated, resulting in a consistent efficiency of the system. Specific frequency ranges can be affected by the depth of the cavity and thus individual adjustments to the respective applications can be created. It was shown that an estimation of the absorption coefficient using the JCAL model offers good possibilities for industrial applications. In this study, a cavity of $D=108 \mathrm{~mm}$ length was selected to reduce the subharmonic components in the partial load range of the axial fan. Reductions of up to $2.9 \mathrm{~dB}$ in overall sound pressure level were realized. It was found that the change in cross-section due to the cavity has a greater influence on the sound reduction than the perforation of the MPPs. An extension of the absorber surface offers the possibility to generate higher sound absorption's for this system. In addition to the sound reduction, a small increase in the sound radiation at the blade passing frequency of the fan was generated by the MPA. This undesirable side effect may be due to the surface irregularities of the MPPs. The integration of MPAs into heat exchanger modules is a simple and compact way of optimizing cooling systems acoustically while maintaining aerodynamic efficiency.

\section{Conflict of interest}

Author declared no conflict of interests.

\section{References}

1. F. Czwielong, F. Krömer, S. Becker: Experimental investigations of the sound emission of axial fans under the influence of suction-side heat exchangers, in 25th AIAA/CEAS Aeroacoustics Conference, Vol. AIAA 2019-2618 Session: Acoustic/Fluid Dynamics Interactions X, 20-23 May 2019, Delft, The Netherlands. 2019. https://doi.org/10.2514/ 6.2019-2618.

2. A. Lucius, M. Schneider, S.S.-D. Bortoli, T. Gerhard, T. Geyer: Aeroacoustic simulation and experimental validation of sound emission of an axial fan applied in a heat pump, in Proceedings of the 23rd International Congress on Acoustics, DEGA-Akustik, Berlin, Germany. 2019.

3. C. Ocker, T.F. Geyer, F. Czwielong, F. Krömer, S. Becker, M. Merkel, W. Pannert: Experimental investigation of the impact of 3d-metal-printed perforated leading edges on airfoil and axial fan noise, in AIAA AVIATION 2020 FORUM, AiAA American Institute of Aeronautics and Astronautics, Reston, VA, USA. 2020, 2529 p. https://doi.org/10.2514/ 6.2020-2529.

4. F. Krömer, F. Czwielong, S. Becker: Experimental investigation of the sound emission of skewed axial fans with leading-edge serrations. AiAA 57, 12 (2019) 5182-5196. https://doi.org/10.2514/1.J058134.

5. T.M. Biedermann, P. Czeckay, N. Hintzen, F. Kameier, C. Paschereit: Applicability of aeroacoustic scaling laws of leading edge serrations for rotating application, in Acoustics,
Vol. 2, Multidisciplinary Digital Publishing Institute, Basel, Switzerland. 2020, pp. 579-594. https://doi.org/10.3390/ acoustics2030030.

6. F. Czwielong, F. Krömer, P. Chaitanya, S. Becker: Experimental investigation of the influence of different leading edge modifications on the sound emission of axial fans downstream of a heatexchanger, in Proceedings of the 23rd International Congress on Acoustics, DEGA-Akustik, Berlin, Germany. 2019.

7. C. Liu, Z. Ji, Z. Fang: Numerical analysis of acoustic attenuation and flow resistance characteristics of double expansion chamber silencers. Noise Control Engineering Journal 61, 5 (2013) 487-499. https://doi.org/10.3397/1/3761043.

8. M. Möser, G. Müller: Handbook of Engineering Acoustics. Springer-Verlag Berlin Heidelberg, 2013. https://doi.org/ 10.1007/978-3-540-69460-1.

9. F. Czwielong, S. Floss, M. Kaltenbacher, S. Becker: Influence of a micro-perforated duct absorber on sound emission and performance of axial fans. Applied Acoustics 174 (2021) 107746. https://doi.org/10.1016/j.apacoust.2020.107746.

10. S. Floß, M. Kaltenbacher, G. Karlowatz: Application and simulation of micro-perforated panels in hvac systems, in Conference: 10th International Styrian Noise, Vibration \& Harshness Congress: The European Automotive Noise Conference, 20-22 June 2018, Graz, Austria. 2018, https://doi. org $/ 10.4271 / 2018-01-1514$.

11. S. Floss, F. Czwielong, F. Krömer, S. Becker, M. Kaltenbacher: Achieving axial fan sound reduction with micro-perforated absorbers, in Fortschritte der Akustik DAGA 2019 45. Deutsche Jahrestagung für Akustik, 18-21 März 2019, Rostock, DEGA-Akustik. 2019, pp. 1410-1413.

12. B. Dong, D. Xie, F. He, L. Huang: Noise attenuation and performance study of a small-sized contra-rotating fan with microperforated casing treatments. Mechanical Systems and Signal Processing 147 (2021) 107086. https://doi.org/ 10.1016/j.ymssp.2020.107086.

13. S. Allam, M. Abom: Fan noise control using micro- perforated splitter silencers. Journal of Vibration and Acoustics 136, 3 (2014) 031017. https://doi.org/10.1115/1.4027245.

14. S. Sacks, M. Åbom: Modal filters for mitigation of in-duct sound. Acoustical Society of America 29 (2016). https://doi. org $/ 10.1121 / 2.0000473$.

15. S. Allam, M. Ảbom: Noise reduction for automotive radiator cooling fans, in FAN 2015, The Institution of Mechanical Engineers, London, GB. 2015.

16. S. Floss, F. Czwielong, S. Becker, M. Kaltenbacher: Microperforated panels for noise reduction. e \& i Elektrotechnik und Informationstechnik 138, 3 (2021) 171-178. https://doi. org/10.1007/s00502-021-00889-y.

17. D.Y. Maa: Potential of micro-perforated panel absorbers. Journal of the Acoustical Society of America 104, 5 (1998) 2861-2866. https://doi.org/10.1121/1.423870.

18. J.Y. Chung, D.A. Blaser: Transfer function method of measuring in-duct acoustic properties II Experiment. Journal of the Acoustical Society of America 68, 3 (1980) 914-921. https://doi.org/10.1121/1.384779.

19. L. Jaouen, F.X. Bécot: Acoustical characterization of perforated facings. Journal of the Acoustical Society of America 129, 3 (2011) 1400-1406. https://doi.org/10.1121/1.3552887.

20. N. Atalla, F. Sgard: Modeling of perforated plates and screens using rigid frame porous media. Journal of Sound and Vibration 303, 5 (2007) 195-208. https://doi.org/10.1016/j. jsv.2007.01.012.

21. DIN EN ISO 10534: Acoustics - Determination of sound absorption coeffcient and impedance in impedance tubes Part 2: Transfer function method. Berlin Beuth Verlag, Berlin, Germany, 2010. 
22. J.F. Allard: Propagation of Sound in Porous Media. Elsevier, London, 2015. https://doi.org/10.1002/9780470747339.

23. I. O. f. S. DIN EN ISO 5801: Industrial fans-performance testing using standardized airways. 2007.

24. F.J. Krömer: Sound emission of low-pressure axial fans under distorted inflow conditions, doctoralthesis. FAU University Press, Erlangen, Germany, 2018. https://doi.org/10.25593/ 978-3-96147-089-1.

25. F.J. Zenger, A. Renz, M. Becher, S. Becker: Experimental investigation of the noise emission of axial fans under distorted inflow conditions. Journal of Sound and Vibration 383 (2016) 124-145. https://doi.org/10.1016/j.jsv.2016.07.035.

26. E. DIN, 7235: Akustik-labormessungen an schalldämpfern in kanälen-einfügungsdämpfungsmaß, Strömungsgeräusch und Gesamtdruckverlust. Berlin Beuth Verlag, Berlin, 2010.
27. I. O. f. S. DIN EN ISO 3745: Acoustics - determination of sound power levels and sound energy levels of noise sources using sound pressure - precision methods for anechoic rooms and hemi-anechoic rooms. Berlin Beuth Verlag, Berlin, 2012.

28. I.H. Abbott, A.E. Von Doenhoff: Theory of wing sections, including a summary of airfoil data. Courier Corporation, New York, USA, 1959.

29. L. Jaouen, F.-X. Bécot: Acoustical characterization of perforated facings. The Journal of the Acoustical Society of America 129, 3 (2011) 1400-1406. https://doi.org/10.1121/ 1.3552887 .

30. M. Möser: Technische Akustik. Springer-Verlag, Heidelberg, Germany, 2012.

Cite this article as: Czwielong F. Floss S. Kaltenbacher M. \& Becker S. 2021. Sound reduction in heat exchanger modules by integrating plate absorbers with sub-millimeter openings. Acta Acustica, 5, 35. 